\title{
Policies for Enhancing Success or Failure? A Glimpse into the Language Policy Dilemma of one Bilingual African State
}

\author{
Clement Dlamini \\ University of the Witwatersrand \\ dlaminicl@yahoo.co.uk
}

\begin{abstract}
This paper is an attempt to extend the debate on language policy development, which so far has been dominated by African linguists and language policy planners. Little attempt has been made in the mathematics education field to highlight the discriminatory nature of some language policies, be they national or institutional polices. Dominant societies have used language to discriminate against other minority groups in numerous societies all over the world. Most research studies on language as a linguistic capital have been conducted by members of the privileged groups and the recommendations that have accompanied such studies do not provide a practical solution as to how the 'suppressed' minorities could be 'liberated' and be able to participate in their societies in a meaningful way. While language policies have affected immigrants in most European countries, it is a different story in Africa. In Africa the people most affected by discriminatory policies are the indigenous population. The paper presents a case study of one country in Africa where the language policy has been a big obstacle to indigenous learners' quest to gain access to tertiary education. The paper compares learners' achievement in English language and mathematics. I argue in this paper that proficiency in English language does not necessarily mean success in mathematics.
\end{abstract}

From monolingualism to bilingualism and finally to multilingualism is a journey that many African scholars have travelled, not by choice but propelled by their quest to gain access to social goods. Gee (1999) uses the phrase 'social goods' to mean anything that constitutes a source of power, e.g. money, qualifications, social status, etc. In some contexts, African children are born monolingual, communicating only in their maternal language. They are then initiated into a second language, the language of instruction, and finally into languages of particular discourses, e. g. the language of mathematics. In all professions and disciplines there are specific languages that give a certain identity to that particular discourse. In most cases the specific language of the practice or discipline is conveyed in a natural language which should be mastered before the discipline is mastered.

In most African countries masters of professional discourses have had to master the natural language in which the discourse is conveyed as well as the language of the practice in which they are engaged in.
For example, in Francophone and Anglophone Africa French and English are media of instruction in schools and second languages for a majority of learners in most former colonies of France and Britain.

The question of why second languages have been used as the media of instruction has been debated by many scholars over the years. Some have put blame on Africa's former colonial powers and poor educational language policies that have been drawn up by the newly independent African states after attaining independence (Alexander, 2001; Alidou, 2001; Bamgbose, 1999; Bokamba, 1995). Almost all previously colonized African countries have opted for the language of the colonizing power for various reasons, such as unification of different tribes in cases of multilingual countries and cost effectiveness in adopting an already established language of government, business and instruction, thus endorsing these languages as languages for development (Alexander, 2001; Wodak \& Corson, 1997). These languages have been elevated to the status of a capital and therefore have become social 
goods that every citizen endeavours to gain access to. English language has become the linguistic capital (Barwell, 2002; Zevenbergen, 2000) in Anglophone countries and a legitimate medium of instruction in schools. According to Edwards (1994) and Paulston (1999), cited in Barwell (2002), political decisions determine the roles of language in education. They assert that the questions of who gets which language in school "are bound up with issues of access, power and dominance" (p. 206). This leads to what Barwell (2002) refers to as 'linguistic discrimination' where some languages are favoured over others. This discrimination creates a situation where the dominant language becomes a form of capital (Zevenbergen, 2000). Who is now dominating who in independent African countries where governments are composed of people whose mother tongue is not English and yet in these countries English is the dominant language?

While difficulties of learning in a second language have been documented in different studies both in the field of linguistics and the field of mathematics and science education (Cummins, 2001; Setati \& Adler, 2001; Moschkovich, 1999; Zevenbergen, 2000), and while there has been documented successes in bilingual education programmes (Enge \& Chesterfield, 1996; Komarek, 2000; Okombo \& Rubgumya, 1996), there has not been any significant changes in language policies of most African states. Hence, the difficulties faced by Africans in accessing social goods have remained tied to language. For example, the language policies still hold the assumption that proficiency in the language of instruction at school level is an indicator of success in tertiary education. A number of African universities require or consider proficiency in the language of instruction as one of their entry requirements. This belief has also been reinforced by studies that have suggested that, in mathematics for instance, proficiency in the language of instruction is a factor in the acquisition of mathematical concepts and therefore influences the degree of achievement in mathematics (e.g. Fernadez \& Neilsey, 1986; Howie, 2002; Mestre, 1988; Secada, 1992; Young, 1988;) that is, in cases where English is the language of learning and teaching (LoLT), language proficiency has been associated with mathematics achievement.

A number of researchers who have been involved in bi/multilingual research have gone beyond the issue of language proficiency and have looked at other factors that contribute to the failure or success of mathematics teaching and learning in schools. These researchers have actually looked at mathematics as a language that has its own register and have explored practices that distinguish mathematics from other disciplines and looked at ways of how the discourse practices can be used to enhance success in mathematics (e.g. Barwell, 2003, in Britain; Gorgio \& Planas, 2001, in Spain; Moschkovich, 2002, in the United States of America; Setati \& Adler, 2001, in South Africa; Zevenbergen, 2000, in Australia).

This paper argues for revision of language policies that have since placed indigenous citizens at a disadvantage probably because they are a barrier for access to social goods. The paper argues that policies designed through the notion of language proficiency as an indicator of success in schools and in the world of work are in fact hindering development and excluding people from participating in the development of their countries. This argument is supported by data (which is presented later) that suggest that some language policies can exclude indigenous people from accessing social goods, such as gaining access to tertiary education, to jobs, and other economic benefits they should be enjoying in their own countries. The data is presented here as an example of how one county in Africa is 'wasting' the cream of it's would be intellectuals through what I perceive to be unsound language policies. This country is an example of such cases in Africa where the learners' home language is not the language of instruction and where the language policy has excluded a majority of capable indigenous people from participating in the technological and scientific fields of development. Acting on the premise that language proficiency is an indicator of mathematics achievement, data is presented as a point of debate as to how these studies hold in the context of African countries.

\section{An analytical glance at the effect of language proficiency on other disciplines}

Most African countries are plagued by unemployment, diseases, high levels of poverty, the use of primitive technology, and underdevelopment among a host of other problems. Although there are numerous factors that have contributed to these problems, most of them have been a result of poor national policies. Most policies seem to have been adopted from their colonial masters and hence seem to be a continuation of the assimilation policies of the West. The 
language-in-school policies, which are most often driven by national language policies, have proved to be the major source of underachievement of indigenous Africans because of the use of a second language in teaching and learning environments. The use of a second language implies that indigenous learners first have to learn the language of instruction before they can master the discipline of the learning area. It is, therefore, logical that proficiency should play a major role in the academic achievements of learners in any learning discipline. The findings of the studies mentioned earlier do not come as a surprise. It was probably a result of these studies that influenced the design of most language policies in Africa.

However, a number of these studies have only focused on low achieving learners and not high achievers. Another weakness of these studies is that proficiency has not been adequately discussed and defined to such an extent that it is understood in the context of the study in question. It is therefore difficult to ascertain what language competencies a learner should possess to be seen to be proficient enough in the language of instruction. At what level of schooling or of the education system does language proficiency matter? Most studies that have shown a relationship between mathematics achievement and proficiency in English, for example, were conducted at the primary school level where most indigenous learners are still learning the language of instruction. At this level it is expected that learners will not be masters of a discipline that is in the language they are still learning.

In this paper I argue that although lack of language proficiency may affect one's chances of succeeding in other disciplines, it does not necessarily cause low performance in mathematics. I present an analysis of the General Certificate of Education (GCE) examination results in Swaziland which shows that high achievers in mathematics have low proficiency (assuming that the GCE examinations are a measure of proficiency) in the language of instruction.

I begin my argument by presenting the language policies of the country and its tertiary institutions' admission policies and show how these policies have succeeded to strangulate the country's development in terms of possible technological advances and curbing unemployment through the training of the cream of the product of its school system.

\section{Swaziland's national language policy and language-in-school policy}

Although Swaziland is fast becoming a heterogeneous society, it is still referred to as monolingual with siSwati being the only indigenous language. SiZulu is also spoken in southern Swaziland. When Swaziland was colonized by the British in the early 1900, English became the language of business and writing. That is, all written communication was only in English. At the time, all indigenous languages in the country had no written register. After gaining independence in 1968, the status of siSwati was elevated to the status of an official language and this status has remained at that since then. Although siSwati and English are official languages, almost all government correspondence and communication is in English, notwithstanding the fact that more than $90 \%$ of Swazis speak fluent siSwati (Mbatha, 2001).

According to Mbatha (2001) the hegemony of English is what has actually retained English as an official language, unlike in other African multilingual countries where it was viewed as a language of national unity. In Swaziland it was retained as an official language because it is a language of wider communication, a lingua franca in dealing with other countries. Mbatha (2001) contends that it was retained because it was viewed as a language of development, which has a large body of knowledge and also because it is a "symbol of civilized, educated people" (p. 89). The early British system of education influenced the present status of English as a language of communication in that all government communication, such as parliament bills and laws of the country are in English. Whenever a need for translation arises, such translations are normally from English to siSwati and not vice versa.

The Swaziland education system follows a transitional bilingual-education policy with a weak emphasis on siSwati. Transitional bilingualism is a type of bilingualism that allows the first or main language to be used as a medium of instruction and as a tool to facilitate the transition to the medium of instruction (Garcia, 1997), which is English. While the national language policy suggests that siSwati and English have equal status, in practice this is not the case. The transitional-education policy is somewhat contradictory to the national policy in that it elevates English to a higher status than siSwati. 
Officially, siSwati is the medium of instruction in Grades 1 and 2 only, while English is the medium of instruction from Grade 3 up to tertiary education level. However, in practice there is a strong pull towards English even in Grades 1 and 2. This is because there are no guidelines for using siSwati as a medium of instruction. This weak emphasis on siSwati is worsened by the fact that all teaching and learning materials are written in English from Grade 1 to tertiary education level. English language, as a subject, is a hurdle for failure in schools. That is, government policy states that a child who fails English language is deemed to have failed the grade level and should not proceed to the next grade. It is thus known locally as a 'failing subject'. In school reports you would find comments like "failed because of English Language".

\section{Assumptions}

Architects of this policy had noble intentions of forcing the learner to pass English language at an early stage of the learning process so that the learner is able to face real world challenges in the world of work. However, what this policy assumes is that a child who fails English language in Grade 3 cannot cope with demands of English language and other subjects in Grade 4. Actually, it suggests that the complexity of English language and other subjects increase with each year of study. It also suggests that the level of English of the subject in a subsequent grade is so complex that a child who passes all other subjects and fails English will not have 'enough English' to succeed in the following grade level. These policies are also extended to tertiary institutions.

In the University of Swaziland, for example, a good pass in English language is a requirement for admission into most faculties. For example, to pursue a Bachelor of Science (BSc) degree, a credit grade ( $\mathrm{C}$ or better) in English Language in the General Certificate of Education (GCE) is among the entry requirements. Again this requirement suggests that a BSc degree requires proficiency in English and that the level of proficiency that enabled a learner to pass other subjects in the GCE is not good enough for university mathematics and science programmes. Another assumption made is that English Language as a subject is the only subject where learners can learn all the necessary language skills and that the English language examinations are an effective measure of proficiency. It is probably why the University of Swaziland selects English language as one of the indicators of success in the BSc programmes.

\section{Shocking statistics}

The statistical results presented here were completely unexpected considering the fact that studies have suggested that there is a strong correlation between mathematics and English Language. Although most of these studies were conducted in Europe and America, other studies conducted in Africa have also alluded to this finding (e.g. Howie, 2002).

My analysis has been generated from data that was drawn from an ongoing study that I am currently conducting in Swaziland. The larger study is conducted in one school where the majority of learners are indigenous Swazis. All indigenous Swazis are second language speakers of English. The analysis that is presented in this paper is based on data that was collected even before the main study began to find out how learners in Swaziland fared in English and mathematics, the two subjects that are considered in Swaziland to be gateways to higher learning.

The data was solicited from the Examination Council of Swaziland (ECOS). The data that was collected was the GCE grades for English language and mathematics for 2006 for all the candidates of the school where the larger study was conducted, and for all high achieving mathematics learners in Swaziland. This data was collected to find out how the results of the learners of the school compare with the national English language and mathematics grades. Since the study was about mathematics high achieving learners, all grades of candidates in the school and in the whole country who had obtained a credit grade (see Table 1) in mathematics were selected together with their corresponding English language grade. These results were analysed using the Excel spreadsheet.

The number of mathematics grades and their English language grades were counted and represented as shown in Tables 2 and 3 below. The correlation coefficients for 2006 for BeNguni ${ }^{1}$ (pseudonym) school candidates and for the national candidates were calculated to show the degree of

\footnotetext{
${ }^{1}$ BeNguni school has large enrolment of indigenous learners. The school is where the major study is being conducted. Data from this school is used here because discourse practices and achievement patterns in this school may be similar to other typical schools where indigenous learners are a majority. Furthermore, schools like BeNguni are a majority in Swaziland.
} 
correlation between the two subjects. The formula for calculating the coefficients that is used in the Excel spreadsheet is

$$
r=\frac{\sum(X-\bar{X})(Y-\bar{Y})}{\sqrt{\sum(X-\bar{X})^{2}(Y-\bar{Y})^{2}}}
$$

where $r$ is the Pearson product-moment correlation, and $X$ and $Y$ are scores of the two subjects while

$\bar{X}$ and $\bar{Y}$ are the means. This means that Excel divides the sums of products of the deviation of an $\mathrm{X}$ value from its mean and the deviation of a $\mathrm{Y}$ value from its mean by the product of the squared deviations.
It further shows that three candidates obtained an upper A grade in mathematics. This is $10 \%$ of all the A's in Swaziland for the year 2006 (see Table 3). The three candidates were among the top $1.6 \%$ candidates who obtained an upper A grade in mathematics. The other two candidates who obtained an upper A grade in mathematics and a credit grade in English language were among the only 24 candidates $(1.3 \%)$ in the whole country who achieved this feat. One of these candidates was the only one who obtained a 1 grade in mathematics and 5 grade in English language in the whole country. This is a remarkable achievement by the country's standards.
Table 2 shows the mathematics grades and their corresponding English language grades for BeNguni school in 2006 and the national grades of the subjects for the same year. The number of learners who did not gain a credit in English language is calculated and then expressed as percentage of the total number of candidates. Further analysis reveals the number and percentage of learners that obtained exceptional results in mathematics but did not gain a credit in English language. Figures 1-3 show diagrammatic representations of the grades as shown by the plots.
Table 2: A comparison of the 2006 English Language and Mathematics grades for BeNguni High School candidates

\begin{tabular}{|c|c|c|c|c|c|c|c|c|c|c|}
\hline $\begin{array}{c}\text { Mathematics } \\
\text { symbols }\end{array}$ & \multicolumn{10}{|c|}{ Number of corresponding English Language grades } \\
\cline { 2 - 11 } & $\mathbf{1}$ & $\mathbf{2}$ & $\mathbf{3}$ & $\mathbf{4}$ & $\mathbf{5}$ & $\mathbf{6}$ & $\mathbf{7}$ & $\mathbf{8}$ & $\mathbf{9}$ & Totals \\
\hline $\mathbf{1}$ & 0 & 0 & 1 & 0 & 1 & 0 & 0 & 1 & 0 & 3 \\
\hline $\mathbf{2}$ & 0 & 0 & 0 & 0 & 0 & 0 & 0 & 0 & 1 & 1 \\
\hline $\mathbf{3}$ & 0 & 0 & 1 & 2 & 3 & 6 & 5 & 2 & 0 & 19 \\
\hline $\mathbf{4}$ & 0 & 0 & 0 & 0 & 0 & 0 & 5 & 5 & 0 & 10 \\
\hline $\mathbf{5}$ & 0 & 0 & 0 & 0 & 0 & 2 & 4 & 1 & 2 & 9 \\
\hline $\mathbf{6}$ & 1 & 0 & 2 & 1 & 2 & 2 & 8 & 5 & 1 & 22 \\
\hline Totals & 1 & 0 & 4 & 3 & 6 & 10 & 22 & 14 & 4 & 64 \\
\hline
\end{tabular}

Candidates who did not gain a credit in English language $=40(62.5 \%)$ Candidates who obtained A or B in mathematics but no credit in English language $=19(29.7 \%)$

Correlation coefficient $=0.014$
Table 1 shows the GCE O-Level grading system. The table shows that grades 1-6 (equivalent to A-C) are categorized as a credit, 7-8 (equivalent to D-E) are a pass and 9 (equivalent to $U$ ) is a fail.

The following tables show comparisons of English language and mathematics grades in the GCE OLevel examinations for 2006.

Table 2 shows that there were 64 candidates in this school who obtained a credit grade in mathematics.

Table 1: The GCE O-Level grading system

\begin{tabular}{|c|l|}
\hline Numerical symbol & Alphabetical symbol \\
\hline 1 & Upper A \\
2 & Lower A \\
\hline 3 & Upper B \\
4 & Lower B \\
\hline 5 & Upper C \\
6 & Lower C \\
\hline 7 & D \\
\hline 8 & E \\
\hline 9 & U - ungraded \\
\hline
\end{tabular}

Also shown in the table is that there is one candidate who did not gain a credit in English language. Actually, this candidate gained credit grades in all the other subjects (two other upper A's and three B's with an aggregate ${ }^{2}$ of 17). Table 2 is re-represented in Figure 1.

Figure 1 shows that for all the A, B and upper C grades in mathematics (square dots) all the corresponding English language grades occupied an upper $y$-value in the graph. The positioning of the English language grades in the graph shows that in this school the best mathematics achievers did not get an English language grade that was better than their mathematics grade. A similar analysis can be made for Table 3 .

\footnotetext{
${ }^{2}$ An aggregate is calculated by adding the best grades (including English language) from each subject group.
} 


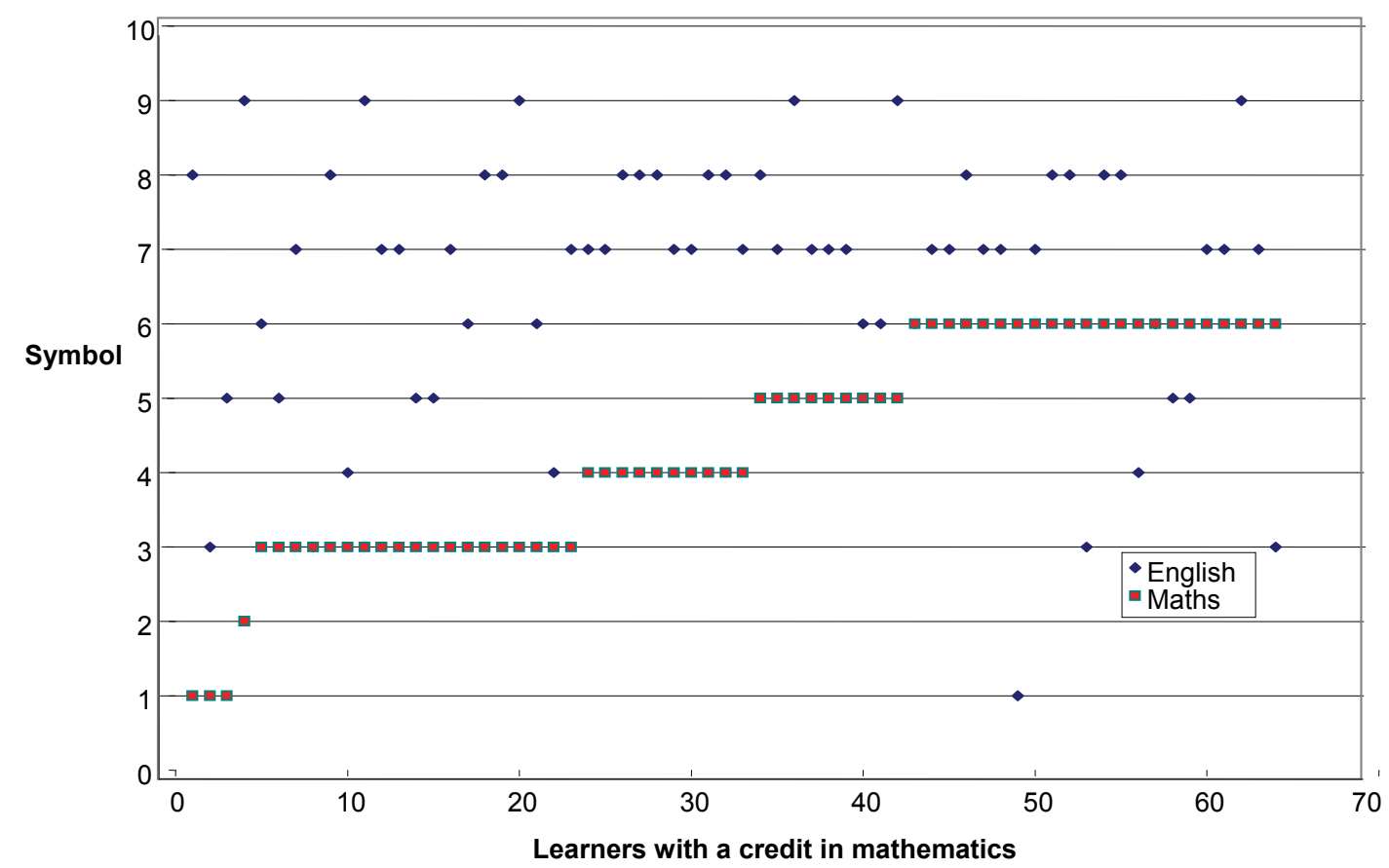

Figure 1: The 2006 English Language and Mathematics grades for BeNguni High School candidates

Table 3: A comparison of the GCE 2006 national English Language and Mathematics grade

\begin{tabular}{|c|c|c|c|c|c|c|c|c|c|c|}
\hline \multirow{2}{*}{$\begin{array}{c}\text { Mathematics } \\
\text { symbols }\end{array}$} & \multicolumn{1}{|c|}{ Number of corresponding English Language symbols } \\
\cline { 2 - 11 } & $\mathbf{1}$ & $\mathbf{2}$ & $\mathbf{3}$ & $\mathbf{4}$ & $\mathbf{5}$ & $\mathbf{6}$ & $\mathbf{7}$ & $\mathbf{8}$ & $\mathbf{9}$ & Totals \\
\hline $\mathbf{1}$ & 9 & 4 & 5 & 3 & 1 & 2 & 4 & 2 & & 30 \\
\hline $\mathbf{2}$ & 9 & 8 & 15 & 9 & 7 & 12 & 24 & 9 & 3 & 96 \\
\hline $\mathbf{3}$ & 20 & 22 & 45 & 24 & 29 & 58 & 94 & 64 & 16 & 372 \\
\hline $\mathbf{4}$ & 10 & 6 & 23 & 14 & 13 & 25 & 67 & 44 & 17 & 219 \\
\hline $\mathbf{5}$ & 13 & 6 & 25 & 13 & 17 & 44 & 100 & 58 & 31 & 307 \\
\hline $\mathbf{6}$ & 12 & 15 & 46 & 37 & 38 & 94 & 285 & 215 & 83 & 825 \\
\hline Totals & 73 & 61 & 159 & 100 & 105 & 235 & 574 & 392 & 150 & 1849 \\
\hline
\end{tabular}

Candidates who did not gain a credit in English language $=1116(60.35 \%)$

Candidates who obtained A or B in mathematics but no credit in

English language $=344(18.6 \%)$

Correlation coefficient $=0.2827$

An analysis for the national grades of all candidates who had obtained a credit in mathematics for the years; 2001, 2002 and 2003 showed that, in 2001, out of a total of 965 learners who had gained a credit in mathematics, $604(62.6 \%)$ did not gain a credit in English language. In 2002 and 2003, 66.6\% and $63.9 \%$ respectively did not gain a credit in English language. What is of major concern is that about $20 \%$ of candidates who obtained exceptional grades (A and $\mathrm{B}$ ) in mathematics were consistently not gaining a credit in English language in all the years for which the analysis was done. In 2001, 2002, 2003 and 2006, $17.7 \%, 18.7 \%, 16.1 \%$ and $18.6 \%$ respectively did not gain a credit in English language.
The analysis presented above shows that:

- One fifth of the best mathematics high achieving learners in Swaziland do not gain a credit in English language.

- A majority (more than $60 \%$ ) of high achievers in mathematics do not gain a credit in English Language

Table 4 shows the correlation coefficients that were calculated to find the linear relationship between the mathematics grades for high achievers in mathematics and their corresponding English language grades. The analysis shows a low positive correlation of about 0.3 . It also suggests that the 
relationship between the two subjects was not affected by a change in population. For example, the doubled population of the 2006 cohort of 1849 from the 2001 cohort of 965 candidates did not introduce any significant difference in the correlation coefficient.

Table 4: Correlation coefficients in different years

\begin{tabular}{|c|c|c|}
\hline Year & $\begin{array}{c}\text { Total number of } \\
\text { candidates }\end{array}$ & $\begin{array}{c}\text { Correlation } \\
\text { coefficient }\end{array}$ \\
\hline 2001 & 965 & 0.2980 \\
\hline 2002 & 1217 & 0.2899 \\
\hline 2003 & 1114 & 0.3422 \\
\hline 2006 & 1849 & 0.2827 \\
\hline
\end{tabular}

The correlation coefficient $r$ is an index that ranges between -1 and +1 . This index reflects the extent of a linear relationship. If $r$ tends towards -1 it means there is a negative correlation between two variables. In this case that would mean candidates who obtain high grades in mathematics would tend to obtain low grades in English. If the index is zero that means there is no relationship between the variables being compared. This analysis has shown that the correlation coefficients are consistently closer to zero for the periods where data was provided, which suggests that there is a low correlation between mathematics and English in Swaziland.

The scatter plots in Figures 2 and 3 illustrate a low correlation. The correlation coefficient between the scores was calculated at 0.014 , which indicates a close to zero correlation between the two subjects. This correlation coefficient is far lower than the national coefficients shown in Table 4.
In summarizing the findings I should point out that the data presented in Tables 2 and 3 and Figures 1-3 reflect a true reality of the Swazi situation. Sampling errors were eliminated by taking the whole population of learners in both the school and the national statistics.

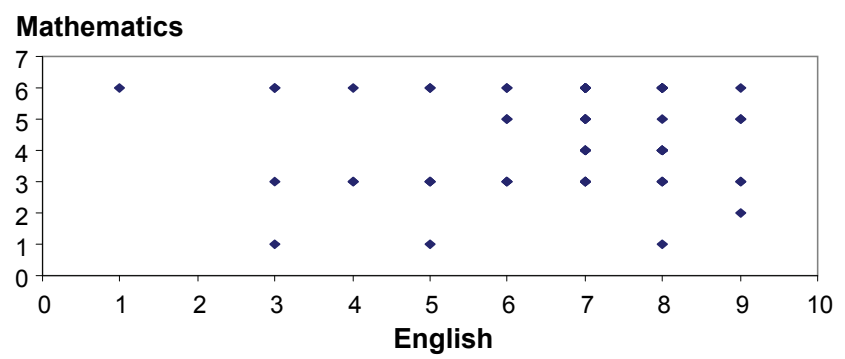

Figure 2: Scatter plot of Mathematics and English Language grades of BeNguni high school for 2006

The data presented here suggests that high achievement in mathematics is not solely influenced by high achievement in English language. The low correlation coefficients for BeNguni mathematics high achievers suggest that there may be no correlation between English language and mathematics grades of Swazi indigenous learners.

The data has thus prompted the following conclusions:

- English language is a poor predictor of future performance for learners in Swaziland in the mathematics field of study

- High achievers in mathematics may not be high achievers in English language

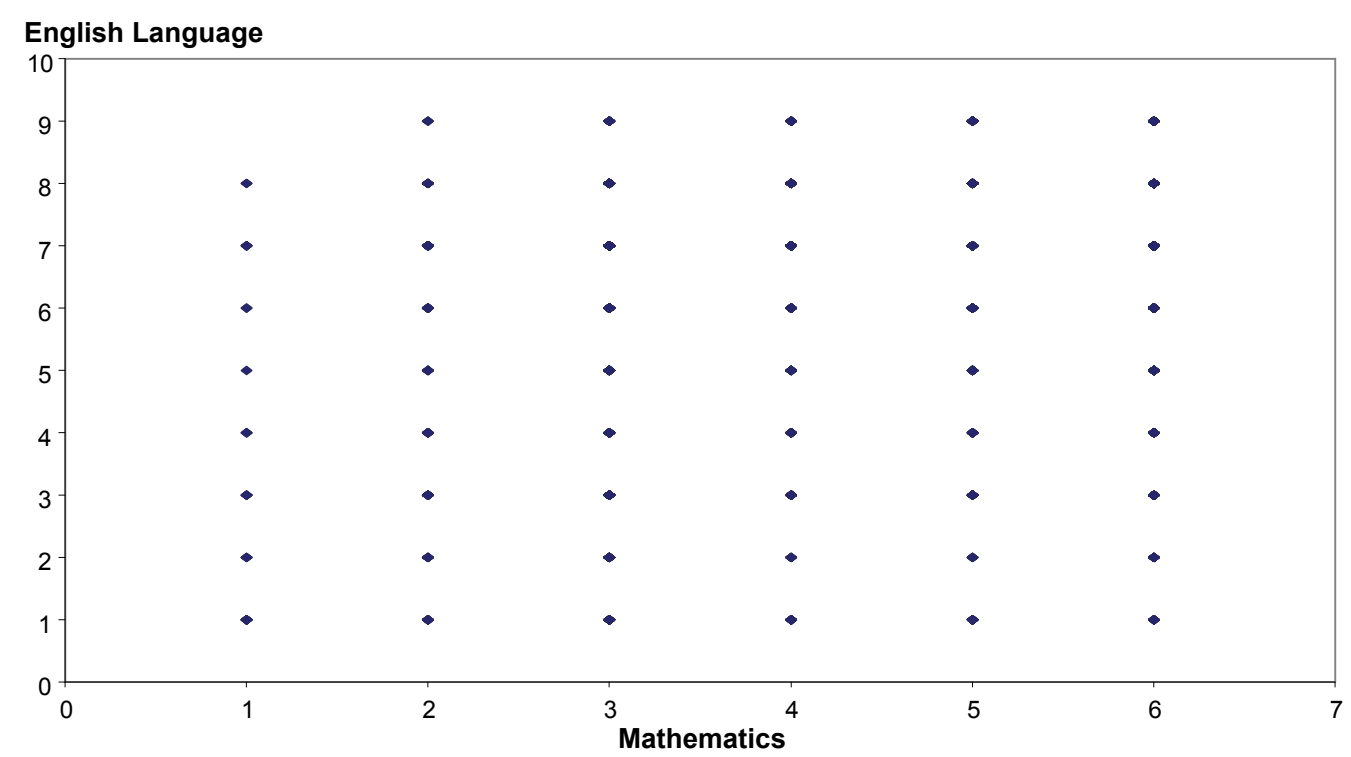

Figure 3: Scatter plot of the GCE 2006 national English Language and Mathematics grades 
It should be noted here that although correlation coefficients measure the degree of linearity between two variables, it does not measure causality. In this case it does not indicate that high performance in mathematics causes low performance in English language. However, the trend as presented above seems to suggest that candidates in Swaziland who do well in mathematics may have low proficiency in English language.

\section{Conclusion}

The policy of higher education institutions of accepting only a credit in English language is a severe blow to the country's development as the country is losing more than $60 \%$ of potentially capable citizens through this policy. The results discussed here probably hold for similar situations in other African countries. As mentioned earlier, the studies that associated proficiency in English with mathematics achievement were conducted in countries and in environments that were quite different from the Swazi situation. The results have shown that there is need to revise or enforce language policies that are aimed at enhancing development in various countries. The school policies of failing learners because of failing a second language are counterproductive. They seem to discriminate against the indigenous populations. The data presented earlier suggests that the language-in-school policy in Swaziland is successful in discriminating against the indigenous population as it discards more $60 \%$ of mathematically capable citizens yearly. The indigenous population is eliminated in the school system as they increase the repetition rates and eventually drop out of school, thus denied participation in the national development of their countries.

The low correlation between English and mathematics is proof that the language policies in Africa were indeed poorly planned, and that they were possibly based on empirical evidence from the West. The mere fact that a good pass in English language is an entry requirement into mathematics and science programmes in some institutions of higher learning in most Anglophone states is an indication that it could have been based on an assumed high correlation between these disciplines. While this assumption may be true in some contexts, the findings in this paper suggest that it is not always true in some African contexts. The results have also shown that if the language policies of countries where the medium of instruction is in a second language are left unchecked, they will continue to discriminate against indigenous populations who will always be denied access to social goods.

\section{References}

Alexander, N. (2001) Bilingual education as a transitional strategy in post colonial Africa. In N. Alexander, Reports on mother-tongue education. Cape Town: University of Antwerpen UFSIA, University of Cape Town, Project for the Study of Alternative Education in South Africa.

Bamgbose, A. (1999). African language development and language of planning. Language and development in Africa. Social Dynamics, 25(1), 13-31.

Barwell, R. (2002). Linguistic discrimination and mathematics education research. In P. Valero \& O. Skovesmose (Eds.), Proceedings of the Third International Mathematics Education and Society Conference, Part 1 (pp. 206-216), Helsingor, Denmark.

Barwell, R. (2003). The participation of learners of English as an additional language (EAL) in mathematics classroom interaction. Unpublished doctoral dissertation. University of Bristol, UK.

Bokamba, E. G. (1995). Politics of language planning in Africa: Critical choices for the $21^{\text {st }}$ century. Discrimination through language in Africa? In M. Pütz (Ed.). Perspectives on Namibian Experience. Berlin: Mouton de Gruyter.

Cummins, J. (2001). The academic and political discourse of minority language education: Claims and counter-claims about reading, academic language, pedagogy, and assessment as they relate to bilingual children's educational development. Paper presented at the $3^{\text {rd }}$ ISB Conference, University of Bristol.

Enge, K. I., \& Chesterfield, R. (1996). Bilingual education and student performance in Guatemala. International Journal of Educational Development, 16(3), 291-302.

Fernandez, R. M., \& Nielsen, F. (1986). Bilingualism and Hispanic scholastic achievement: Some baseline results. Social Science Research, 15, 43-70.

Garcia, O. (1997). Bilingual Education. In F. Coulmas (Ed.), The Handbook of Sociolinguistics (pp. 405-419). Oxford: Blackwell.

Gee, J. P. (1999). An introduction to discourse analysis: Theory and method. London: Routledge.

Gorgio, N., \& Planas, N. (2001). Teaching mathematics in multilingual classrooms. Educational Studies in Mathematics, 47, 7-33.

Howie, S. (2002). English language proficiency and contextual factors influencing mathematics achievement of secondary school pupils in South Africa. Den Haag: CIP-Gegevens Koninklike Bibliotheek. 
Komarek, K. (2000). Education for all African children: The state of "organized communication" in the classroom. Paper presented at the UNESCO conference of education for all, Dakar.

Mbatha, T. (2001). Mother tongue education: The case of Swaziland's language-in-education policy. In N. Alexander, Reports on Mother-tongue Education. Cape Town: University of Antwerpen UFSIA, University of Cape Town, Project for the Study of Alternative Education in South Africa.

Mestre, J. P. (1998). The role of language comprehension in mathematics and problem solving. In R. R. Cocking \& J. P. Mestre (Eds.), Linguistic and cultural influences on learning mathematics: The psychology of education and instruction (pp. 201-220). Hillsdale: Lawrence Erlbaum Associates.

Moschkovich, J. (1999). Supporting the participation of English language learners in mathematical discussions. For the learning of mathematics, 19(1), 11-19.

Moschkovich J. (2002, July). Methodological challenges in studying bilingual mathematics learners. Paper presented at the Pre-PME conference meeting of the multilingual mathematics group, University of East Anglia, Norwich.

Okombo, O., \& Rubgumya, C. (1996). Synopsis of research findings on languages of instruction and their implications for educational policies in Africa. Newsletter for the Association for the Development of Education in Africa, 8(4), 5-7.
Secada, W. G. (1992). Race, ethnicity, social class, language, and achievement in mathematics. In D. A. Grouws (Ed.), Handbook of research on mathematics teaching and learning (pp. 623-660). New York: Macmillan Publishing.

Setati, M., \& Adler, J. (2001). Between languages and discourses: Language practice in primary multilingual mathematics classrooms in South Africa. Educational Studies in Mathematics, 43(3), 241-269.

Wodak, R., \& Corson, D. (Eds.) (1997). Language planning and education. Encyclopaedia of language and education: Language policy and political issues in education (pp 13-22). Kluwer Academic Publishers.

Young, M. B. (1988). Academic performance of limited English proficiency Indian elementary students in reservation schools: Year two report of the National Evaluation of Services for Limited English Proficient Native American Students. Washington: Office of Panning, Budget and Evaluation.

Zevenbergen, R. (2000). "Cracking the code" of mathematics classrooms: School success as a function of linguistic, social, and cultural background. In J. Boaler (Ed.), Multiple Perspectives on Mathematics Teaching and Learning. London: Ablex Publishing. 